\title{
Radio tagging reveals the roles of corpulence, experience and social information in ant decision making
}

\author{
Elva J. H. Robinson - Thomas O. Richardson • \\ Ana B. Sendova-Franks • Ofer Feinerman • \\ Nigel R. Franks
}

Published online: 18 February 2009

(C) Springer-Verlag 2009

\section{Erratum to: Behav Ecol Sociobiol \\ DOI 10.1007/s00265-008-0696-Z}

Robinson EJH, Richardson TO, Feinerman O, SendovaFranks AB, Franks NR (2009) Radio tagging reveals the roles of corpulence, experience and social information in ant decision making.

We regret that the RFID microtransponder dimensions and weight were given incorrectly in the second paragraph of the materials and methods section.

This should read: The microtransponders measured 500× $500 \times 120 \mu \mathrm{m}$ and had a mean weight of $89 \mu \mathrm{g}(\mathrm{SD}=0.01)$ including the weight of the glue.

The online version of the original article can be found at http://dx.doi. org/10.1007/s00265-008-0696-z)

E. J. H. Robinson $(\bowtie) \cdot$ T. O. Richardson $\cdot$ N. R. Franks

University Research Centre for Behavioural Biology and Ant Lab,

School of Biological Sciences, University of Bristol,

Woodland Road,

Bristol BS8 1UG, UK

e-mail: Elva.Robinson@bristol.ac.uk

T. O. Richardson - A. B. Sendova-Franks

Department of Mathematics and Statistics, BIT,

University of the West of England,

Coldharbour Lane,

Bristol BS16 1QY, UK

O. Feinerman

Computational Biology Center,

Memorial Sloan-Kettering Cancer Center,

1275 York Avenue, Box 460, New York, NY 10021, USA 